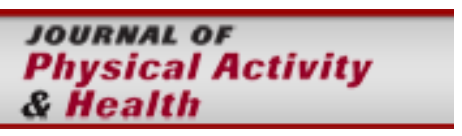

\title{
Long term health outcomes associated with an exercise referral scheme: An observational longitudinal follow-up study
}

\begin{tabular}{|r|l|}
\hline Journal: & Journal of Physical Activity \& Health \\
\hline Manuscript ID & JPAH.2018-0442.R1 \\
\hline Manuscript Type: & Public Health Practice \\
\hline Keywords: & public health, physical activity, chronic disease \\
\hline \multicolumn{2}{l}{} \\
\end{tabular}

\section{SCHOLARONE Manuscripts}


LONG TERM ERS OUTCOMES

2

3 Background Exercise referral schemes (ERSs) support inactive adults, who have

4 chronic health conditions, to become physically active. Uncertainty exists regarding

5 the effectiveness of ERSs, with few studies evaluating their long term impact. The

6 aims of this paper were to evaluate the long term impact (12 months) of participation

7 in an ERS on self-reported physical activity (PA) and a range of health related

8 outcomes.

10 Methods Data were analysed for participants of a 24-week ERS who attended a week

1152 follow-up between July 2015-2017. PA and health related outcomes collected at 12 weeks 1, 24 and 52 were analysed using Friedman's test and Wilcoxon signed ranks 13 test.

15 Results 273 participants attended the week 52 follow-up. Self-reported PA 16 significantly increased by a median of 636 MET minutes at week 52 . There were also 17 significant improvements in body mass index, systolic blood pressure, mental wellbeing and health related quality of life.

20 Conclusions For every 8 participants referred to this 24-week ERS, one participant 21 went on to show long term improvements in at least one health indicator. The evidence base requires further long term evaluations to confirm these findings across a range of ERS providers, and would benefit from the inclusion of device based measurement of PA. 
LONG TERM ERS OUTCOMES

\section{Introduction}

Despite increasing knowledge of the benefits of physical activity ${ }^{1}(\mathrm{PA})$, there has been a global decline in PA levels over recent decades ${ }^{2}$. Physical inactivity is a public health challenge associated with both a substantial health ${ }^{1}$ and economic burden $(\$ 53.8$ billion per annum worldwide) $)^{3}$. Furthermore, individuals with chronic health conditions are less likely to be active than those without ${ }^{4}$, despite the secondary prevention benefits of $\mathrm{PA}^{5}$.

One approach to PA promotion has been exercise referral schemes (ERSs), a form of non-medical intervention or 'social prescription'. Such schemes were developed in the UK in the early $1990 s^{6}$, and have since been adopted in several other countries ${ }^{7}$. They aim to support inactive adults who have chronic health conditions to become more physically active in order to improve their health ${ }^{8}$. More than two decades since their development, the evidence base for the efficacy of ERSs is comparably small and inconclusive ${ }^{9}$, with further research required to understand which ERSs work, for whom and why ${ }^{6}$.

Of the existing research, an area of focus has been the impact of participation on selfreported PA levels and health outcomes. To date, systematic reviews have found no consistent evidence of an increase in PA following participation in an ERS, or an improvement in outcomes such as body mass index (BMI), blood pressure (BP), or psychological wellbeing ${ }^{6,9}$. However, reviews have been based on a small number of randomised controlled trials $(\mathrm{RCTs})(\leq 8)$, with relatively short follow-up periods $(\leq 6$ months). Few observational studies have been published which examine the impact 
51 of ERSs in real world practice settings ${ }^{10,11}$. There have also been few studies, of any design, which examine the impact of participation on long term changes in PA and health outcomes, such as 12 months or more following referral ${ }^{12-14}$. Therefore, the aims of this study were to evaluate the long term impact (12 months) of participation in an ERS on self-reported PA and a range of health related outcomes, using an observational longitudinal follow-up design.

Methods

The scheme

The ERS was delivered in the UK borough of Tameside, which is an area with evident health inequalities ${ }^{15}$, and high levels of chronic health conditions and physical

64 inactivity ${ }^{15}$. The scheme was 6 months in duration, with 4 routine contact points (3060 minute consultations), hosted within local leisure centres. Consultations were 66 delivered by exercise professionals holding a minimum of a Register of Exercise

67 Professionals (REPs) level 3 qualification in exercise referral. REPs is an independent public register that provides a system of regulation for all professionals involved in the exercise and fitness industry, with level 3 enabling the practitioner to work as an advanced fitness instructor and in exercise referral ${ }^{16}$. During an initial consultation an exercise professional made an assessment of the participant's health status, goals and preferences. Based on this information, a programme of opportunities to become physically active, tailored to the participants' needs and preferences, was then offered.

74 This included options for supervised group-based activities, or independent activities, within the local leisure facilities (e.g. use of gym, swimming pool and PA classes) or 
LONG TERM ERS OUTCOMES

76 the community (e.g. health walks, walking football groups, home exercises).

77 Participants then had follow-up consultations with the exercise professional at week

6,12 , and 24 , where changes in health status were assessed and behaviour change support provided, with data collection only at week 52 . The ERS provided 12 months

80 of subsidised access to its leisure facilities and supervised classes. The majority of 81 community-based activities were free, or incurred a small pay-as-you-go fee.

82

Eligibility for referral

84

Referrals were accepted from health care professionals (including allied professions,

e.g. physiotherapists) for residents of the borough aged $\geq 18$ years, identified as

87 inactive with a chronic health condition or significant health risk factors. Exclusion criteria included contraindications to $\mathrm{PA}^{17}$. The primary referral pathways for the scheme were: (1) existing cardiovascular disease (CVD), or significant risk factors such as hypertension; (2) metabolic syndrome or diabetes; (3) mental health condition;

(4) respiratory disease; (5) overweight or obese $\left(\geq 25 \mathrm{~kg} / \mathrm{m}^{2}\right)$;

(6) musculoskeletal condition which was chronic in nature, including pain and high risk of falls, and; (7) any other condition whose symptoms could be improved by PA (i.e. multiple sclerosis, 94 cancer).

Outcome measures

The content of the data collected was dictated by the developers of the scheme, based upon the Standard Evaluation Framework for PA interventions ${ }^{18}$ recommendations, and was collected by the exercise professional at weeks $1,12,24$ and 52 . The 
101 outcomes included: current PA level (International Physical Activity Questionnaire 102 Short Form ${ }^{19}$ (IPAQ-SF)), health related quality of life (HRQoL) (EuroQol five

103 dimensions three level questionnaire ${ }^{20}$ (EQ-5D-3L) and EuroQol five dimensions 104 visual analogue scale ${ }^{20}$ (EQ-5D VAS)), mental wellbeing (Warwick-Edinburgh Mental 105 Well-being Scale ${ }^{21}$ (WEMWBS)), BMI, BP, alcohol consumption, and smoking status.

Data management

109 Anonymised data for referrals made to the scheme between July 2015 - July 2017

110 were extracted for secondary analysis. Participants who attended the week 52 follow111 up were included for analysis in this study. Participants gave informed consent at the 112 initial consultation for their anonymised data to be used for research purposes. Prior 113 ethical approval was granted by the University of Salford ethics committee (HSCR 15114 124).

116 Statistical analysis

118 Statistical analyses were performed using IBM SPSS version 23 (SPSS, Inc., Chicago,

119 IL, USA). Demographics of referrals were explored using descriptive statistics.

120 Outcomes were analysed for participants with data available at week 1 (baseline), 24

121 (scheme completion point) and 52 (follow-up point), on a variable by variable basis.

122 The distribution of outcome measures was determined to be non-normal. Therefore,

123 Friedman's test was used to examine differences in outcome measures between three

124 time points. If the result was significant $(p \leq 0.05)$, post hoc tests (Wilcoxon signed 125 ranks) were performed with a Bonferroni adjustment applied ( $p \leq 0.017)$. 
LONG TERM ERS OUTCOMES

\section{Results}

128

129 Participant flow

130

131 Of 2104 referrals made between July 2015 - July 2017, 1609 entered the scheme. Of 132 these, 471 had dropped out early, 515 were actively participating between weeks 1

133 and 24, and 623 had completed the scheme (attended week 24). Of those who had 134 completed the scheme, 230 had not yet reached the week 52 follow-up point and have 135 been excluded from this analysis. Of the remaining 393 participants, 273 (69.5\%) 136 attended a week 52 follow-up in-person or via telephone consultation. A further 120 137 participants (30.5\%) did not have a follow-up (76 unable to establish contact, 22 time 138 elapsed beyond week 52, 20 declined, 2 died) (Figure 1).

140 Participant characteristics

142 The characteristics of participants who did or did not attend a week 52 follow-up are 143 presented in Table 1. Participants who attended the follow-up and were therefore 144 included in this analysis, were more likely to be female (56\%), Caucasian (96\%), and 145 from the most deprived quintile of Tameside (Q1, 37.4\%). Participants were most 146 frequently referred from primary care medical practices (42.9\%), a National Health 147 Service health trainer service (20.1\%), or a weight management service (17.3\%). The 148 most common reasons for referral were for having multiple $(\geq 3)$ health conditions 149 (33\%), being overweight or obese (17.6\%), having a musculoskeletal condition $150(16.1 \%)$ or existing CVD or significant risk factors (14.7\%). Demographics, source of 
151 referral, and primary referral condition did not differ significantly between those who

152 did or did not attend the follow-up (Chi square $p>0.05$ ) with the exception of age;

153 those who attended were significantly older $(\mathrm{t}(385)=2.306, p=0.022)$.

154

155 Participant goals

156

157 A total of 192 participants $(71.4 \%)$ had met their long term goals. The most frequently 158 reported goals were to reduce BMI (50\%), increase or maintain PA levels $(27 \%)$, 159 improve aspects of physical health such as BP (16\%), and improve physical fitness $160(11 \%)$

161

Physical activity

164 There was a significant increase in self-reported PA (MET mins per week) between 165 weeks 1 (mdn 0) and 24 (mdn 660), which was maintained at week 52 (mdn 636) $166\left(X^{2}(2)=219.9, p<.001\right)($ Table 2). Post hoc tests showed that the differences were 167 significant between weeks 1 and $24(Z=-11.8, p<.001)$, and weeks 1 and $52(Z=-$ $16811.9, p<.001)$

170 For comparison with previous research 6,9 , the percentage of participants who were 171 physically active for $\geq 90$ minutes per week was calculated. At week $1,17.3 \%$ were active $\geq 90$ minutes per week at any intensity, rising to $76 \%$ at week 24 , but declining to $72.7 \%$ at week $52\left(X^{2}(2)=231.6, p<.001\right)$. The differences in classification were

174 significant between weeks 1 and $24(Z=-11.4, p<.001)$, and weeks 1 and $52(Z=-$ $17511.2, p<.001)$. 
LONG TERM ERS OUTCOMES

177 Considering only moderate-vigorous intensity PA, the percentage of participants who

178 were physically active for $\geq 90$ minutes per week increased from $5.5 \%$ at week 1 , to $17948 \%$ at week 24 , declining to $40.2 \%$ at week $52\left(X^{2}(2)=212.5, p<.001\right)$. A proportion 180 of participants were active below this threshold $(17.3 \%$ at week 52$)$, and were 181 therefore not completely inactive, as can be seen in Table 3 . The differences in 182 classification were significant between all three time points (all $p<.001$ ). Taking the 183 conservative assumption that all those lost to follow-up made no improvement in PA 184 level, 11 referrals need to be made for one participant to become long term active ( $\geq 90$ 185 minutes per week at any intensity), or 19 referrals for one participant to become long186 term active at moderate-vigorous intensity.

187

Physical health outcomes

190 Participation resulted in significant reductions in body weight $\left(X^{2}(2)=68.4, p<.001\right)$ 191 and $\mathrm{BMI}\left(\mathrm{X}^{2}(2)=67.5, p<.001\right)$. Compared to week 1 , at week 52 the median reduction 192 in body weight and BMl was $3.3 \mathrm{~kg}$ and $1.28 \mathrm{~kg} / \mathrm{m}^{2}$ respectively (Table 2 ). When categorised according to BMI class, at all three time points the majority of participants were either overweight or obese. Differences in BMI class between the three time

195 points were significant $\left(X^{2}(2, n=222)=9.0, p<0.05\right)$, but only between weeks 24 and $19652(Z=-2.7, p<0.017)$, with a decline in the proportion classified as obese $(-3.1 \%)$, 197 and an increase in the proportion classified as overweight $(+0.9 \%)$ or normal weight $(+2.2 \%)$. 
200 Compliance with BP measurement was the lowest of any outcome, with data available 201 for $29.7 \%$ of participants. There were significant improvements in systolic BP $\left(X^{2}(2)=\right.$ $20232.6, p<.001$ ), with post hoc tests showing significant differences between weeks 1 203 and $24(Z=-4.0, p<.001)$, and weeks 1 and $52(Z=-4.2, p<.001)$. Between weeks 1 204 and 52, systolic BP was reduced by $9 \mathrm{mmHg}$ from 138 (127-148) mmHg to 129 (120205 138) $\mathrm{mmHg}$ (Table 2). There were no significant differences in diastolic $\mathrm{BP}\left(\mathrm{X}^{2}(2)=\right.$ $2065.4, p=.069)$. Taken together, these results indicate that an increase in PA had a 207 beneficial impact on body composition and systolic BP.

208

209 Mental wellbeing

210

211 Compliance with collection of the WEMWBS questionnaire was low, with data

212 available for $38.1 \%$ of participants. Available data demonstrated significant 213 improvements in mental wellbeing $\left(X^{2}(2)=48.9, p<.001\right)$. The WEMWBS score 214 increased from $50(42-58)$ to $53(48-59)$ between weeks 1 and $24(Z=-4.4, p<.001)$, 215 and from $50(42-58)$ to $55(50-60)$ between weeks 1 and $52(Z=-5.9, p<.001)$ (Table $2162)$.

218 Health related quality of life

220 Significant improvements were found in the two measures of health related quality of

221 life, the EQ-5D-3L $\left(X^{2}(2)=41.9, p<.001\right)$ and EQ-5D-VAS $\left(X^{2}(2)=115.5, p<.001\right)$ 222 (Table 2). Between weeks 1 and 24, the EQ-5D-3L score increased from .727 (.587$223.850)$ to $.796(.691-1.000)(Z=-4.3, p<.001)$, which was maintained at week $52(Z=$ $224-6.0, p<.001)$. The EQ5D-VAS score increased from $50(40-70)$ to $70(50-80)(Z=-$ 
LONG TERM ERS OUTCOMES

$2257.3, p<.001)$ between weeks 1 and 24 , which also was maintained at week $52(Z=-$

$2268.8, p<.001)$.

227

228 Lifestyle behaviours

229

230 There were no significant differences in smoking status $\left(X^{2}(2, n=268)=2.2, p>.05\right)$ or

231 frequency of alcohol consumption $\left(X^{2}(2, n=268)=2.1, p>.05\right)$. There were however

232 significant differences in the number of alcohol units consumed per drinking episode

$233\left(\mathrm{X}^{2}(2, \mathrm{n}=268)=28.4, p<.001\right)$. The number of units consumed decreased between

234 weeks 1 and $24(Z=-4.1, p<.001)$, and weeks 1 and $52(Z=-4.5, p<.001)$.

235

$236 \quad$ Number of referrals required

237

238 In total 254 participants showed an improvement of any degree in at least one health

239 indicator. Taking the conservative assumption that all those lost to follow-up made no

240 improvement, eight referrals need to be made to have a positive impact on one person.

\section{Conclusions}

244 This aims of this study were to further previous research by reporting the long term

245 outcomes of participation in an ERS, using an observational longitudinal follow-up 246 design. This was important because to-date more than 600 ERSs are in operation in

247 the $\mathrm{UK}^{6}$, and the evidence base for their efficacy is uncertain. There are a relatively 248 small number of published evaluations, and these are predominantly RCTs evaluating 
249 the short term outcomes of participation, with fewer studies evaluating the sustained 250 impact of participation in the long term ${ }^{6,9}$.

252 The most important findings of this study were that participation led to significant long 253 term improvements in PA level and the majority of health related outcomes. For every

25411 participants referred, one participant went on to report long term PA behaviour 255 change ( $\geq 90$ mins per week), and for every 8 participants referred, one participant 256 went on to show long term improvements in at least one health indicator. This 257 conservatively assumes that those lost to follow-up have not maintained 258 improvements at 12 months. At 6-12 months, there was a significant increase in the 259 proportion of participants achieving $\geq 90$ minutes of PA per week (from $17 \%$ to $73 \%$ at 26012 months). There were also significant improvements in health risk factors such as $261 \mathrm{BMI}$ and BP, as well as mental wellbeing and quality of life. This indicates that 262 participation in an ERS can lead to sustained improvements in PA and health related 263 outcomes beyond the scheme's duration.

265 These findings are important because previous systematic reviews, which are based on a small number of RCTs, but inform policy, have found no consistent evidence for 267 an improvement in these outcomes ${ }^{6,9,22}$. Currently there is a consensus that ERSs 268 have a small impact on short term PA changes, with the long term impact largely 269 unknown ${ }^{9}$. The results of this study support recent research finding significant 270 improvements in PA over the first 6 months of participation, which are maintained in 271 the long term ( $\geq 12$ months $)^{23}$. The findings are also consistent with observational 272 studies and RCTs which found significant improvements in body composition ${ }^{10,11,24}$, 273 systolic $\mathrm{BP}^{13,24}$, quality of life ${ }^{11,25,26}$, and mental wellbeing ${ }^{11,13}$. However, comparison 
274 of outcomes between schemes can be difficult, because as complex interventions with

275 ambiguous guidance, ERSs have heterogeneous delivery models and participants,

276 and they are often designed according to the local context and strategic aims ${ }^{27,28}$. Non-

277 significant impact on lifestyle behaviours such as smoking have previously been

278 reported, albeit rarely ${ }^{29,30}$, and suggest that ERS participation alone is not sufficient to

279 change these behaviours, with additional specialist support required.

280

281 A high number of referrals were made to this ERS, rising from 391 referrals in the first

2826 months of operation to 2104 referrals after 2 years, which may indicate health care

283 professional's satisfaction with the impact of the scheme. The 6 month completion rate

$284(56.9 \%)$ was also relatively high in comparison to previous literature ${ }^{31}$, potentially

285 demonstrating higher participant acceptance than expected. However, the most

286 important limitation of this study is the loss to follow-up of $30.5 \%$ of participants who

287 had reached the week 52 follow-up point. It is not possible to quantify the bias that this

288 introduces, although we note that, other than being younger, those lost to follow-up

289 were not systematically different at baseline. It is possible that those who were not

290 followed up were less likely to have maintained their participation in PA. Another

291 limitation is the self-reporting of PA, as questionnaires are subject to potential bias and

292 subsequent poor validity 32,33 , with over-reporting of moderate-vigorous intensity PA,

293 and under-reporting of light intensity PA ${ }^{34,35}$. Despite this, few studies have assessed

294 PA levels in ERS participants using device based methods ${ }^{36}$, perhaps due to the 295 convenience and low cost of questionnaires ${ }^{37}$. Lastly, this evaluation did not have a

296 control group. However, the role of RCTs in the evaluation of public health

297 interventions operating in real world contexts has received criticism ${ }^{38,39}$. The pressure

298 for community PA interventions to conduct RCTs overlooks the skills, logistics, and 
LONG TERM ERS OUTCOMES

299 finances required to carry out such an evaluation ${ }^{40,41}$, and does not guarantee that an

300 intervention designed according to the local context will have the same success in a

301 different community.

302

303 In conclusion, referral to a 6 month ERS led to significant improvements in PA and a

304 range of health related outcomes, which were sustained in the long term beyond the

305 scheme's duration. This indicates that this scheme was effective in initiating and

306 sustaining long term PA behaviour change. The evidence base requires more long

307 term evaluations to confirm these findings, across a range of ERS providers operating

308 in different contexts, including cost-benefit analyses, and the inclusion of device based

309 measurement of PA to support self-reported outcomes.

310

311 Acknowledgements

312

313 The authors thank all staff at Active Tameside, with specific acknowledgement to those

314 involved in the Live Active exercise referral scheme for their assistance with this study,

315 including the scheme's participants.

316

317 Funding source

318

319 This work was supported by a grant from Sport England and Tameside Metropolitan 320 Borough Public Health Board.

\section{References}

323 


\section{LONG TERM ERS OUTCOMES}

324 1. Lee IM, Shiroma EJ, Lobelo F, et al. Effect of physical inactivity on major non-

325 communicable diseases worldwide: an analysis of burden of disease and life

326 expectancy. Lancet. 2012;380(9838):219-229.

327 2. Ng SW, Popkin B. Time use and physical activity: a shift away from movement 328 across the globe. Obes Rev. 2012;13(8):659-680.

329 3. Ding D, Lawson KD, Kolbe-Alexander TL, et al. The economic burden of 330 physical inactivity: a global analysis of major non-communicable diseases.

$331 \quad$ Lancet. 2016;388(10051):1311-1324.

332 4. Brawner CA, Churilla JR, Keteyian SJ. Prevalence of physical activity is lower 333 among individuals with chronic disease. Med Sci Sports Exerc.

$334 \quad 2016 ; 48(6): 1062-7$.

335 5. Warburton DER, Bredin SSD. Health benefits of physical activity: a systematic 336 review of current systematic reviews. Curr Opin Cardiol. 2017;32(5):541-556.

337 6. Pavey TG, Anokye N, Taylor AH, et al. The clinical effectiveness and cost338 effectiveness of exercise referral schemes: a systematic review and economic 339 evaluation. Health Technol Assess (Winch Eng). 2011;15(44):1-254.

340 7. Arsenijevic J, Groot W. Physical activity on prescription schemes (PARS): do 341 programme characteristics influence effectiveness? Results of a systematic 342 review and meta-analyses. BMJ Open. 2017;7:e012156.

343 8. NICE. Physical activity: exercise referral schemes. Public health guideline 54. 344 https://www.nice.org.uk/guidance/ph54. Published September 2014. Accessed $345 \quad$ July 242018. 
346 9. Campbell F, Holmes M, Everson-Hock E, et al. A systematic review and

347 economic evaluation of exercise referral schemes in primary care: a short

348 report. Health Technol Assess (Winch Eng). 2015;19(60):1-110.

349 10. McGeechan GJ, Phillips D, Wilson L, et al. Service evaluation of an exercise on 350 referral scheme for adults with existing health conditions in the United Kingdom. $351 \quad$ Int J Behav Med. 2018; 25(3):304-311.

352 11. Stewart L, Dolan E, Carver P, et al. Per-protocol investigation of a best practice 353 exercise referral scheme. Public Health. 2017;150:26-33.

12. Harrison RA, Roberts C, Elton PJ. Does primary care referral to an exercise programme increase physical activity one year later? A randomized controlled trial. J Public Health. 2005;27(1):25-32.

13. Isaacs AJ, Critchley JA, Tai SS, et al. Exercise evaluation randomised trial (EXERT): a randomised trial comparing GP referral for leisure centre-based exercise, community-based walking and advice only. Health Technol Assess (Winch Eng). 2007;11(10):1-165.

14. Murphy SM, Edwards RT, Williams N, et al. An evaluation of the effectiveness and cost effectiveness of the national exercise referral scheme in Wales, UK: a randomised controlled trial of a public health policy initiative. J Epidemiol Community Health. 2012;66(8):745-753.

15. Public Health England. Tameside local authority health profile 2018. https://fingertips.phe.org.uk/profile/health-profiles. Published July 2018. Accessed July 24, 2018. 


\section{LONG TERM ERS OUTCOMES}

368 16. Register of Exercise Professionals. REPs Categories.

369 https://www.exerciseregister.org/reps-categories. Accessed November 5, 2018.

370 17. American College of Sports Medicine. ACSM's guidelines for exercise testing

371 and prescription. 10th ed. Philadelphia, PA: Lippincott Williams and Wilkins;

2017.

373 18. Cavill N, Roberts K, Rutter H. Standard evaluation framework for physical

$374 \quad$ activity interventions.

375 http://webarchive.nationalarchives.gov.uk/20170110171012/https://www.noo.org

376 .uk/core/frameworks/SEF_PA. Published September 2012. Accessed July 26

$377 \quad 2018$.

378 19. IPAQ. Guidelines for data processing and analysis of the international physical 379 activity questionnaire (IPAQ). https://sites.google.com/site/theipaq/scoring$380 \quad$ protocol. Published November 2005. Accessed July 262018.

381 20. EuroQol Group. EuroQol-a new facility for the measurement of health-related 382 quality of life. Health policy. 1990;16(3):199-208.

383 21. Tennant R, Hiller L, Fishwick R, et al. The Warwick-Edinburgh mental well-being 384 scale (WEMWBS): development and UK validation. Health Qual Life Outcomes. $385 \quad 2007 ; 5(1): 63$.

386 22. Williams NH, Hendry M, France B, et al. Effectiveness of exercise-referral 387 schemes to promote physical activity in adults: systematic review. $\mathrm{Br} J \mathrm{Gen}$ $388 \quad$ Pract. 2007;57(545):979-986. 
389 23. Martín-Borràs C, Giné-Garriga M, Puig-Ribera A, et al. A new model of exercise

390 referral scheme in primary care: is the effect on adherence to physical activity

$391 \quad$ sustainable in the long term? A 15-month randomised controlled trial. BMJ

392 Open. 2018;8(3).

393

24. Lee ASW, Griffin SJ, Simmons RK. An evaluation of the effectiveness of 'active for life': an exercise referral scheme in West Suffolk. Public Health. 2009;123(10):670-672.

25. Gusi N, Reyes MC, Gonzalez-Guerrero JL, et al. Cost-utility of a walking programme for moderately depressed, obese, or overweight elderly women in primary care: a randomised controlled trial. 2008; 8: 231.

26. Sørensen J, Sørensen JB, Skovgaard T, et al. Exercise on prescription: changes in physical activity and health-related quality of life in five Danish programmes. Eur J Public Health. 2011;21(1):56.

27. Henderson HE, Evans AB, Allen-Collinson J, et al. The 'wild and woolly' world of exercise referral schemes: contested interpretations of an exercise as medicine programme. Qual Res Spor, Exerc Health. 2018; 10(4): 505-523.

28. Oliver EJ, Hanson CL, Lindsey IA, et al. Exercise on referral: evidence and complexity at the nexus of public health and sport policy. Int J Sport Policy and Politics. 2016; 8(4): 731-736.

29. Taylor AH, Doust J, Webborn N. Randomised controlled trial to examine the effects of a GP exercise referral programme in Hailsham, East Sussex, on modifiable coronary heart disease risk factors. J Epidemiol Community Health. 1998;52(9):595-601. 
LONG TERM ERS OUTCOMES

412 30. Ward M, Phillips CJ, Farr A, et al. Heartlinks-a real world approach to effective 413 exercise referral. Int J Health Promot Educ. 2010;48(1):20-27.

414 31. Pavey T, Taylor A, Hillsdon M, et al. Levels and predictors of exercise referral 415 scheme uptake and adherence: a systematic review. J Epidemiol Community $416 \quad$ Health. 2012;66(8):737-44.

417 32. Haskell WL. Physical activity by self-report: a brief history and future issues. $J$ 418 Phys Act Health. 2012;9(Suppl 1):5-10.

33. Helmerhorst HHJF, Brage S, Warren J, et al. A systematic review of reliability and objective criterion-related validity of physical activity questionnaires. Int $J$ Behav Nutr Phys Act. 2012;9(1):1-55.

34. Cerin E, Cain KL, Oyeyemi AL, et al. Correlates of agreement between 423 accelerometry and self-reported physical activity. Med Sci Sports Exerc. 2016;48(6):1075-1084.

35. Steene-Johannessen J, Anderssen SA, Van der Ploeg HP, et al. Are self-report measures able to define individuals as physically active or inactive? Med Sci Sports Exerc. 2016;48(2):235-244.

36. Gallegos-Carrillo K, García-Peña C, Salmerón J, et al. Brief counseling and exercise referral scheme: a pragmatic trial in Mexico. Am J Prev Med. 2017;52(2):249-259.

37. Strath SJ, Kaminsky LA, Ainsworth BE, et al. Guide to the assessment of physical activity: clinical and research applications. Circulation. 2013; 128(20): 2259-2279. 
LONG TERM ERS OUTCOMES

434 38. Pettman TL, Armstrong R, Doyle J, et al. Strengthening evaluation to capture 435 the breadth of public health practice: ideal vs. real. J Public Health. $436 \quad 2012 ; 34(1): 151-155$.

437 39. Rutter H, Savona N, Glonti K, et al. The need for a complex systems model of 438 evidence for public health. Lancet. 2017;390(10112):2602-2604.

439 40. Gidlow C, Johnston LH, Crone D, et al. State of the art reviews: methods of $440 \quad$ evaluation: issues and implications for physical activity referral schemes. $A m \mathrm{~J}$ $441 \quad$ Lifestyle Med. 2008;2(1):46-50.

442 41. Department of Health. Exercise referral systems: a national quality assurance 443 framework.

444 http://webarchive.nationalarchives.gov.uk/20130107105354/http://www.dh.gov.u 445 k/prod_consum_dh/groups/dh_digitalassets/@dh/@en/documents/digitalasset/d 446 h_4079009.pdf. Published April 2001. Accessed July 262018 
LONG TERM ERS OUTCOMES

Table 1. Demographics of participants who attended or did not attend the week 52 follow-up consultation. CVD, cardiovascular disease.

\begin{tabular}{|c|c|c|c|c|}
\hline & \multicolumn{2}{|c|}{ Attended } & \multicolumn{2}{|c|}{ Did not attend } \\
\hline & $n$ & $\%$ & $n$ & $\%$ \\
\hline \multicolumn{5}{|l|}{ Gender } \\
\hline Female & 153 & 56 & 69 & 57.5 \\
\hline Male & 120 & 44 & 51 & 42.5 \\
\hline \multicolumn{5}{|l|}{ Age } \\
\hline Mean (SD) & \multicolumn{2}{|c|}{$57.7(14.1)$} & & $54(15.2)$ \\
\hline$<65$ years & 175 & 64.1 & 81 & 67.5 \\
\hline$\geq 65$ years & 97 & 35.5 & 34 & 28.3 \\
\hline Missing & 1 & 0.4 & 5 & 4.2 \\
\hline \multicolumn{5}{|l|}{ Ethnicity } \\
\hline Caucasian & 262 & 96 & 110 & 91.7 \\
\hline Asian & 8 & 2.9 & 7 & 5.8 \\
\hline Mixed & - & - & 3 & 2.5 \\
\hline Black & 3 & 1.1 & - & - \\
\hline
\end{tabular}

Employment status

Full time employed

$58 \quad 21.2$ 
LONG TERM ERS OUTCOMES

Part time employed

22

8.1

10

8.3

Unemployed

42

15.4

26

21.7

Retired/other

151

55.3

53

44.2

Unknown

Quintile of deprivation

1 (most deprived)

102

37.4

45

37.5

2

$77 \quad 28.2$

33

27.5

3

38

13.9

16

13.3

4

42

15.4

15

12.5

5 (least deprived)

10

3.7

6

5

Unavailable

4

1.5

5

4.2

Source of referral

Medical Practice

117

42.9

55

45.8

Health trainers

55

20.1

19

15.8

Physiotherapist

25

9.2

14

11.7

Weight management

$47 \quad 17.3$

15

12.5

Other service

$29 \quad 10.5$

17

14.2

Primary referral condition

CVD/High risk of CVD

40

14.7

18

15 


\section{LONG TERM ERS OUTCOMES}

Diabetes/Pre-diabetes

18

6.6

3

2.5

Mental health

12

4.4

6

5

Respiratory

12

4.4

2

1.7

Musculoskeletal

$44 \quad 16.1$

23

19.2

$\geq$ Overweight

48

17.6

23

19.2

Other condition

9

3.3

1

0.8

Multiple

90

33

44

36.7 
Table 2. Median (IQR) outcomes for each variable, at each time point. $W=$ week. W1W24, W1-W52, and W24-W52 detail the median change in each outcome between the two respective time points. ${ }^{*}<.05,{ }^{* *}<.01$ (Wilcoxon signed rank test)

\begin{tabular}{|c|c|c|c|c|c|c|c|}
\hline Outcome & $n$ & W1 & W24 & W52 & $\begin{array}{l}\text { W1- } \\
\text { W24 }\end{array}$ & $\begin{array}{l}\text { W1- } \\
\text { W52 }\end{array}$ & $\begin{array}{l}\text { W24- } \\
\text { W52 }\end{array}$ \\
\hline Sitting time & 269 & $\begin{array}{l}480(360- \\
660)\end{array}$ & $\begin{array}{l}420(300- \\
480)\end{array}$ & $\begin{array}{l}360 \\
(300- \\
480)\end{array}$ & $-60^{* *}$ & $-120^{\star *}$ & -60 \\
\hline MET mins & 271 & $0(0-198)$ & $\begin{array}{l}660(360- \\
960)\end{array}$ & $\begin{array}{l}636 \\
(248-\end{array}$ & $+660^{* *}$ & $+636^{\star *}$ & -24 \\
\hline $\begin{array}{l}\text { Kilocalorie } \\
\text { expenditure }\end{array}$ & 223 & $0(0-289)$ & $\begin{array}{l}1051 \\
(582- \\
1583)\end{array}$ & $\begin{array}{l}941 \\
(461- \\
1456)\end{array}$ & $+1051^{* *}$ & $+941^{* *}$ & -110 \\
\hline Body weight & 224 & $\begin{array}{l}91.3 \\
(76.75- \\
107.2)\end{array}$ & $\begin{array}{l}89 \text { (76.8- } \\
104.8)\end{array}$ & $\begin{array}{l}88(76.1- \\
104)\end{array}$ & $-2.3^{* *}$ & $-3.3^{* *}$ & $-1 .^{* *}$ \\
\hline BMI & 222 & $\begin{array}{l}32.7 \\
(27.82- \\
37.64)\end{array}$ & $\begin{array}{l}31.68 \\
(27.68- \\
36.91)\end{array}$ & $\begin{array}{l}31.42 \\
(27.51- \\
35.99)\end{array}$ & $-1.02^{* *}$ & $-1.28^{* *}$ & $-0.26^{* *}$ \\
\hline
\end{tabular}




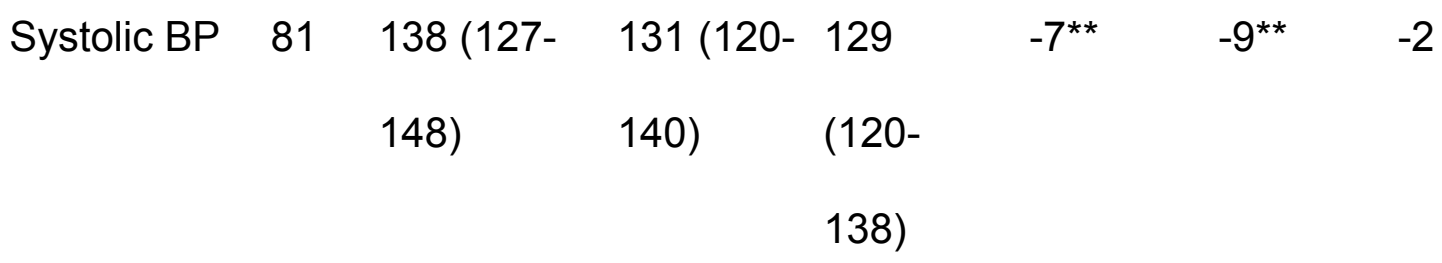

Diastolic BP $81 \quad 80(75-89) \quad 80(73-\quad 81(76-\quad 0 \quad 0 \quad+1 \quad+1$

85) 85)

$\begin{array}{lllllllll}\text { EQ-5D-3L } & 266 & .727(587- & .796 & .796 & +.069^{* *} & +.069^{* *} & 0 \text { * }\end{array}$

$.850) \quad(.691-\quad(.691-$

1.000) 1.000)

EQ-5D VAS $26650(40-70) \quad 70\left(50-70\left(50-\quad+20^{* *} \quad+20^{* *} \quad 0^{* *}\right.\right.$

80) 80)

WEMWBS $10450(42-58) \quad 53\left(48-55\left(50-\quad+3^{* *} \quad+5^{* *} \quad+2^{* *}\right.\right.$

59) 60) 
Table 3. Number of participants who were inactive, or active above or below the 90minutes of moderate-vigorous intensity physical activity (PA) per week threshold at each time point $(N=271)$.

\begin{tabular}{|c|c|c|c|c|c|c|}
\hline \multirow[b]{2}{*}{ PA threshold } & \multicolumn{2}{|c|}{ Week 1} & \multicolumn{2}{|c|}{ Week 24} & \multicolumn{2}{|c|}{ Week 52} \\
\hline & $n$ & $\%$ & $n$ & $\%$ & $n$ & $\%$ \\
\hline 0 minutes & 236 & 87.1 & 85 & 31.4 & 115 & 42.4 \\
\hline 1-89 minutes & 20 & 7.4 & 56 & 20.7 & 47 & 17.3 \\
\hline $90+$ minutes & 15 & 5.5 & 130 & 48 & 109 & 40.2 \\
\hline
\end{tabular}




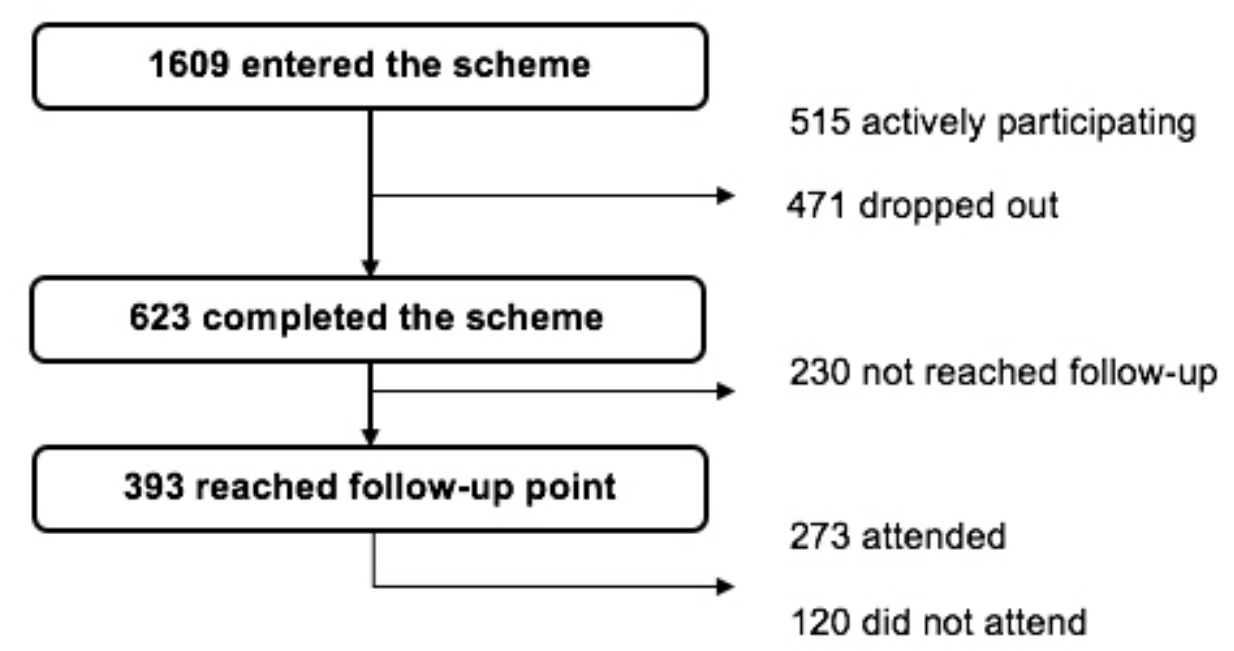

Figure 1 Participant flow through the ERS

$167 \times 88 \mathrm{~mm}(72 \times 72 \mathrm{DPI})$ 